\title{
Characteristics of Conventional and Cascaded Arc Plasma Spray-Deposited Ceramic Under Standard and High-Throughput Conditions
}

\author{
Ramachandran Chidambaram Seshadri $^{1} \cdot$ Sanjay Sampath $^{1}$
}

Submitted: 29 October 2018/in revised form: 23 January 2019/Published online: 4 February 2019

(C) ASM International 2019

\begin{abstract}
Cascaded arc plasma torches have now become mainstream in thermal spray industry incorporating both multiple and single cathode configurations. Although there are anecdotal descriptions available for cascaded arc torches in terms of enhanced melting capability and overall process reliability, a critical and direct comparison of material interaction between the two technologies (cascaded arc and conventional torch configurations) through robust scientific methods is not available. In this article, two commercially available APS torches, namely, the conventional torch (F4MB) and the cascaded arc plasma torch (Sinplex Pro), were compared in the same spray cell using the same control equipment by adopting a systematic set of experiments involving voltage measurements, particle behavior, deposit formation dynamics, and infraredbased spray footprint heat flux quantification. The analysis of the data has led to quantitative correlations between torch configurations. The powder loading study indicated the enhanced melting capability of cascaded arc at equivalent parameters along with expanded and more uniform particle temperature over larger feed rates. The combination of higher feed rate and melt efficiency leads to distinction in coating stress evolution and microstructure. The integrated measurements suggest a scaling parameter that can establish process equivalency parameters to guide the transition from conventional to cascade torches.
\end{abstract}

Sanjay Sampath

sanjay.sampath@stonybrook.edu

Ramachandran Chidambaram Seshadri

csrcn1@gmail.com

1 Center for Thermal Spray Research (CTSR), Stony Brook University, Stony Brook, NY 11790, USA
Keywords atmospheric plasma spray (APS) - diagnostics · in-situ monitoring · on-lineparticle behavior · spray efficiency $\cdot$ stability ofTS process $\cdot$ zirconia

\section{Introduction}

Among the thermal spray processes, the atmospheric plasma spray (APS) process is the most flexible and widely used technology for depositing alloys, composites, and ceramics. Despite being a well-established industrial technology, the reliability and reproducibility of APS coatings are limited due to the transient and dynamic nature of the process (Ref 1). The properties of an APS coating can be a function of three interdependent subsystems: (1) the formation of the plasma jet, (2) injection and processing of the powder material in the plasma jet issuing from the torch and mixing with the surrounding gas, and (3) impact and solidification of the particles on the substrate (Ref 2 ). These subsystems must be diligently monitored, finely controlled, and made to work in a synergistic manner to obtain reliable and repeatable coating deposits. It is well known that the electrode life, thermal efficiency, and performance of the plasma devices are directly or indirectly attributed to the nature of arc fluctuations (Ref 3). A high specific enthalpy along with enough heat transfer from plasma and particle is generally a precondition for high-throughput spraying of refractory materials as it helps to improve the deposition efficiency and spray rate and produce more homogeneous coatings on large complex-shaped parts (Ref 4). Increasing the arc current and/or diatomic gas content can result in an increase in enthalpy, but this is accompanied by a higher rate of anode erosion at the arc attachment point. One solution is to increase the voltage rather than the arc current, and generally, it can be 
done by means of cascaded anode consisting of a stack of copper rings insulated from each other (called neutrodes) and ending with an anode ring on which the arc attaches. This solution improves arc stability, as the movement of the arc is restricted to a small portion inside the anode ring (Ref 5). A commercial plasma torch with a cascaded anode (APG torch from Metco Perkin Elmer) was proposed in the mid-1980s. Today, a few torches are available in the market that uses multiple cathodes, split/extended anodes, cascaded anodes, and the combination of all these modifications (e.g., Triplex Pro, Mettech Axial III, $\mathrm{C}^{+}$Plasma, HE100, Plazjet, etc.) (Ref 6). The latest leap forward concept to stabilize the arc is to use a single cathode, a cascaded anode, and divide the last anode ring into three parts insulated from each other. This concept is implemented in the commercial Sinplex Pro ${ }^{\mathrm{TM}}$ torch from Oerlikon Metco (Ref 7). With the advent of cascaded arc plasma technology, the APS process has expanded into large-scale manufacturing driven by improvement in process stability, deposition rate, deposition efficiency, and economics. In addition, the development of process control using specialized software that controls the process hardware (powder feeder, plasma torch, part handling, etc.) and sensors that are able to monitor the in-flight characteristics of particles (trajectories, velocity, and temperature), substrate temperature, in situ and ex situ stress-modulus measurements has drastically improved the performance and consistency of plasma spraying (Ref 8-10). However, further steps are needed to address the more stringent demands of the traditional applications of plasma spraying and explore emerging markets, e.g., the electronics industry, aero-engine industry, etc., that will require robust and reliable plasma torches (Ref 11). As mentioned earlier, the thermal spray industry is shifting its focus toward high efficiency and high-throughput torches. When coating deposition is made using high enthalpy torches with high throughput, the behavior of particles in the spray plume, i.e., how they interact with plasma/plume, the heat transferred by the particles to the substrate, the transient heat transfer within the coating layers, and the stresses generated in the coating layers, becomes considerably different than coating deposited under normal spray conditions. The effects of such high enthalpy-high-throughput deposition on the parts being sprayed and on the properties of deposits made under such conditions are not clearly deliberated and understood till date. For instance, higher efficiency torches with more uniform plume temperature distribution enable sprayability of significantly higher powder feed rates with associated meltability (Ref 12). However, at higher loading, the coating temperature and stress buildup can be significantly larger leading to major microstructural differences. In order to understand the implications of the plasma spray torch advances mentioned above, an attempt has been made in this research article to understand the particle plume behavior, in-flight particle characteristics, spray footprint heat flux properties, in situ stress evolution, and microstructural aspects of the two configurations of plasma spray torches, namely, the conventional (F4MB) and the cascaded arc torch (Sinplex Pro). These torches were systematically compared using the same controller and diagnostic setup with the same spray powder/feed stock material, i.e., Yttria-Stabilized Zirconia (YSZ). The integrated, quantitative results point to substantial differences in the process-material interactions. In addition to the above, a scaling law was formulated to convert the power level of the conventional torch to the power level of the cascaded arc plasma torch, which would enable thermal spray industries to effectively transition and adopt cascaded arc plasma technology based on a systematic robust scientific methodology, proposed in this investigation.

\section{Experimental Work}

The powder used in this investigation is Oerlikon Metco 204C NS. This is relatively a coarse Hollow Oxide Spherical (HOSP)-grade Yttria-Stabilized Zirconia (YSZ) plasma spray powder having a wide particle size distribution $(-145$ to $+45 \mu \mathrm{m})$. This powder was chosen to obtain porous microstructure and to avoid crack formation in the coating during high-throughput deposition. Two configurations of single electrode torches manufactured by Oerlikon Metco were selected for this comparative evaluation. Among the conventional torches, the F4MB is widely used; hence, it was compared against the Sinplex Pro, which comes equipped with cascaded arc plasma technology (Ref 12). An external radial injection was adopted in all cases which facilitated the powders to be injected at $90^{\circ}$ via a $\varnothing 1.8-\mathrm{mm}$ carbide lined injector located at $4 \mathrm{~mm}$ above the edge of the nozzles. Two different nozzles were also considered for comparison. The cascade (Sinplex Pro) came with 9- and 6.5-mm nozzles, whereas the conventional (F4MB) had standard 8- and 6-mm nozzles. The torches were operated in the same spray cell. The length of the power supply lines, cooling tubes, gas supply hoses, the amount and temperature of water used for cooling, the distribution unit, the power supply module, the (Oerlikon Metco 9MC) control system, and gas flow controllers were kept common for both the torches to carry out an unbiased comparison of the hardware. In order to compare the voltage oscillations of the torches, a power-level comparison study was conducted in which the gas flows were maintained constant (Ar: 50 lpm/ $\mathrm{H}_{2}$ : $6 \mathrm{lpm}$ ), but the power levels were changed $(15,20,30$, 35,40 , and $50 \mathrm{~kW}$ ) in both the torches by suitably tuning the input current values. A Fluke 190 Series II four-channel 
500-MHz Portable Oscilloscope (Fluke Inc, Washington, USA) which was hardwire clamped to the electrode connections at the torch end was used to measure the real-time voltage oscillations during the operation of the torches. A key factor which determines the accuracy of any thermal spray hardware comparison involving radial powder injection is the injection parameter/carrier gas flow rate. Injection optimization was conducted for each condition using detailed methodologies described in our earlier paper (Ref 13). The process involves changing carrier gas in a stepwise manner while monitoring the particle temperature/total emitted infrared intensity using diagnostic sensors. In this investigation, the SprayWatch armed with HiWatch Laser strobe (Oseir Ltd., Tampere, Finland) was used to optimize the injection of powder particles into the plasma. At optimal injection (carrier gas flow rate setpoint), the particle temperature numbers/infrared intensities are the highest demonstrating maximum energy transfer from plasma to particle (Ref 13). The DPV 2000 particle diagnostics system (Tecnar Automation, Quebec, Canada) helped to determine the characteristics of spray particles during the flight phase in a specific area of the spray jet (Ref 14). The DPV plume mapping involved an 81-point grid generated by measurement points separated by $5 \mathrm{~mm}$, which was used to map the temperature and velocity distribution of the particle plume covering a $40 \times 40 \mathrm{~mm}^{2}$ field of view at a $100 \mathrm{~mm}$ spray distance. The particle temperature and velocity were measured for $10 \mathrm{~s}$ in each point of the grid. Furthermore, the measuring volume of the DPV sensor head is $0.5 \mathrm{~mm}^{3}$, which means that only a small area of the spray jet is analyzed per measurement position; hence, a low powder feed rate of $5 \mathrm{gpm}$ is necessary to reduce saturation of measurement volume and to reduce the powder usage during the $\sim 14$ min time length of the DPV diagnosis. The sensor has an automatic XY positioning unit which allows a cross section of the jet to be scanned perpendicularly to the spray axis. In this way, a two-dimensional temperature and velocity distribution of the particles in the spray jet was determined. A near infrared wide-field ensemble particle measurement sensor Accuraspray-g3 (Tecnar Automation, Quebec, Canada) (Ref 15) was also used to measure the in-flight-temperature and velocity of the particles at different powder feed rates $(10,20,40,60,80$, and $100 \mathrm{gpm})$, which helped to determine the threshold/saturation powder loading limit of each torch configuration. The YSZ coatings were deposited on grit-blasted (surface roughness $\sim 8-9 \mu \mathrm{m} \mathrm{Ra}$ ) AISI 316 stainless steel having dimensions $229 \times 25 \times 2.3 \mathrm{~mm}^{3}$. The main reason for choosing the stainless steel substrate was because it provides recognizable deflection during coating deposition due to its high thermal mismatch with YSZ coating; this enables easy measurement of stresses and modulus via in situ curvature measurements. The stress evolution of coatings while spraying over the substrates was measured using an indigenous in situ beam curvature monitoring system based on established principles (Ref 16, 17). This approach allows extraction of layer-by-layer and the overall coating deposition stresses (incorporating thickness) along with the elastic modulus of the coating (Ref 18). To make unbiased comparison of performance attributes of the torches, the power level $(380 \mathrm{~A} \times 93 \mathrm{~V}$ for cascade and $550 \mathrm{~A} \times 65 \mathrm{~V}$ for conventional leading to an equivalent power value of $35 \mathrm{~kW}$ ), gas composition (Ar: $50 \mathrm{lpm} / \mathrm{H}_{2}: 6 \mathrm{lpm}$ ), deposition parameters (an orthogonal meander type spray pattern was adopted comprising of a spray distance: $100 \mathrm{~mm}$, raster speed: $500 \mathrm{~mm} / \mathrm{s}$, and step size: $4 \mathrm{~mm})$ other than powder feed rates $(10,20,40,60$, 80, and $100 \mathrm{gpm}$ ) were maintained constant. A thickness reproducibility experiment was carried out in which the coatings were deposited thrice on fresh grit-blasted virgin substrates at below and above saturation loading limits using the above-mentioned parameter to evaluate the reliability and repeatability of the coatings deposited by the two different kinds of torches (only the large nozzles were considered for this repeatability study: Sinplex $9 \mathrm{~mm}$ and F4MB $8 \mathrm{~mm}$ ). In order to derive a translational/scaling parameter, three coatings were sprayed with each of the torches (Sinplex $9 \mathrm{~mm}$ and F4MB $8 \mathrm{~mm}$ ) under three equivalent power levels $(34,43$, and $51 \mathrm{~kW})$ with a feed rate of $40 \mathrm{gpm}$. The rest of the parameters were kept constant. The relationship plot drawn between the input power levels and evolving stresses was used to formulate the scaling parameter. The coating deposition temperature was continuously monitored through thermocouple instrumentation, placed at the back side of the substrate beam (available in the in situ beam curvature monitoring system), and a FLIR-A600SC Infrared Camera (FLIR Inc, Oregon, USA) was used to measure the front spray footprint temperature at the front face of the substrate. This provides a comprehensive assessment of the deposit formation events. The heat flux delivered by the torches was characterized through the data sets gathered via two different/independent experiments. The first set of experiments were simply heating experiments in which an SS316 substrate covered with a YSZ coating of $350 \mu \mathrm{m}$ thickness was heated by traversing the torch $(500 \mathrm{~mm} / \mathrm{s})$ along the center line of the coated top surface of the substrate at a standoff distance of $100 \mathrm{~mm}$. The torch was cyclically traversed until a steady-state temperature was reached at the center of the YSZ-coated top surface of the substrate. This steady-state temperature was recorded and used as the front temperature, and the back temperature was recorded using the thermocouple attached at the backside of the substrate. This heating experiment was performed using both torches with different nozzles under nine equivalent power levels achieved via a combination of three flow rates 
(Ar/ $\mathrm{H}_{2}(\mathrm{lpm}): 40 / 3,50 / 6$, and 60/9) and three input current settings (cascaded arc torch (I-Amperes): 280, 380, and 480; conventional torch (I-Amperes): 450, 550, and 650). The second set of heat flux data were collected during the spray deposition when the coatings reached $350 \pm 20 \mu \mathrm{m}$ thickness while spraying the powders at different feed rates using different torches under a single equivalent plasma spray deposition condition $\left(\mathrm{Ar} / \mathrm{H}_{2}: 50 / 6 \mathrm{lpm}, 35 \mathrm{~kW}\right.$, $100 \mathrm{~mm}$ spray distance, $4-\mathrm{mm}$ step, and $500-\mathrm{mm} / \mathrm{s}$ raster). The heat fluxes emitted by the torches are quantified using the classical 2D heat flux formula stated in Eq 1.

$\mathrm{d} Q=\left(k_{1}+k_{2}\right) \cdot \frac{\mathrm{d} T}{\mathrm{~d} x}$

where $\mathrm{d} Q=$ heat flux, $\mathrm{d} T=$ temperature difference between the front and back sides of the coated substrate, $\mathrm{d} x=$ thickness of the beam + thickness of the YSZ coating $(2.3+0.350 \mathrm{~mm}), k_{1}=$ thermal conductivity of YSZ $(1.01 \mathrm{~W} / \mathrm{mK}), k_{2}=$ thermal conductivity of stainless steel (43 W/mK). The instantaneous energy (INE) delivered by the torch during a single stroke of the torch on the substrate was calculated simplistically in an empirical manner as shown in Eq 2.

$\mathrm{INE}=\frac{\mathrm{Ls} \times P}{\mathrm{Sr}}$

where Ls is the length of the substrate $(229 \mathrm{~mm}), P$ is the input power $(\mathrm{kW})$ supplied to the torch, and $\mathrm{Sr}$ is the speed of the robot arm $(500 \mathrm{~mm} / \mathrm{s})$. It must be mentioned that the input power supplied to the torch does not end completely in the substrate; for example, a significant portion of at least $30 \%$ is lost through the cooling effect of the water; external losses of heat also occur later in the process, namely, during the mixing of the hot plasma with the surrounding atmosphere before hitting the substrate. These factors are not considered in Eq 2, and it is assumed that most of the energies on the molten particles are transferred to the substrate during impact and subsequent cooling. The examination and characterization of the cross-sectional microstructures of the coatings prepared using standard metallographic practices were conducted using Hitachi TM3000 Scanning Electron Microscope (SEM) (Hitachi High-Tech Corp., Tokyo, Japan). The porosity was analyzed as per ASTM B276 standard on the polished cross section of the coating using an optical microscope (model: Meiji MIL-7100) fortified with image analyzing system. Thermal conductivity measurements were carried out on freestanding coatings using laser flash instrument (LFA, Discovery Xenon Flash DXF 900, TA Instruments, New Castle, DE, USA). The sample preparation method and the methodology to assess the thermal conductivity can be referred elsewhere (Ref 10, 18).

\section{Results and Discussion}

In this article, a process map-based approach is adopted to evaluate the capabilities of the torches. A process map is an integrated set of relationships that link processing to properties and ultimately to performance. The objective is to develop a more fundamental understanding of plasma/particle interactions, droplet/substrate interactions, deposit formation dynamics, and microstructural development, as well as final deposit properties. The first-order process map creates the link between the processing parameters and the spray plume (in-process voltage fluctuations, injection characteristics, in-flight physiognomies under different feed rates). The second-order process map is used to establish the linkages between process microstructures and properties (heat flux calculation of plasma spray coating footprint using infrared profiling, coating microstructure, stress, modulus, thermal conductivity evaluations, etc.). Ultimately, the combination of such maps provides an integrated set of understanding of the complex interaction in thermal spray and allows both fundamental understandings of the process and provides tools for their utilization in the manufacturing sector.

\section{Arc Root Fluctuations and the Associated Current- Voltage Relationships Among Torch Configurations}

The plasma arc can be divided into three regions: cathode region, arc column, and anode attachment. The arc voltage is a sum of the voltages in these three regions (Ref 19). In the case of a single electrode plasma torch, the anode/the arc root attachment causes the plasma to become axially non-symmetric because the arc root has a natural tendency to cross the cold gas boundary layer to attach itself to the anode wall. The plasma gas flow then acts on the arc root attachment exerting a drag force on it, which pushes the arc attachment downstream, while electromagnetic forces try to pull the attachment upstream as described in detail elsewhere (Ref 20). The characteristic features of the voltage drop signal over time for given operating conditions have led to the identification of three distinct modes of operation of the torch (Ref 21), namely: (1) Steady-state mode: characterized by negligible voltage fluctuations and, correspondingly, an almost fixed position of the arc attachment. This mode is not desirable due to the rapid erosion of the anode. (2) Takeover mode: characterized by (quasi-) periodic fluctuations of voltage drop and a corresponding (quasi-) periodic movement of the arc. This operating mode is the most desirable because it allows an adequate distribution of the heat load to the anode and produces well-defined arc fluctuations. (3) Restrike mode: 
characterized by a highly unstable, relatively unpredictable movement of the arc and quasi-chaotic, large amplitude, voltage fluctuations. An arc operating in this mode is very unstable and relatively unpredictable; thus, the arc reattachment phenomenon plays a dominant role in the arc dynamics of plasma torches. Figure 1 shows that the voltage fluctuations in conventional torch irrespective of nozzle size are showing a typical restrike-mode behavior which is characterized by large voltage fluctuations ranging between 16 and $90 \mathrm{~V}$ with a saw tooth-shaped profile. The amplitude of voltage variations is much lower within 90-96 V in case of the cascade (under an eqivalent condition of $35 \mathrm{~kW}$ power level and $\mathrm{Ar} / \mathrm{H}_{2}$ : 50/6 lpm gas flow rate) which proves that takeover mode is in effect. It is worth mentioning here that the electrodes used in this investigation are thorium free and the electrically insulating neutrode arrangement present in the cascaded torch restricts the arc movement between the cathode and anode pair resulting in lower voltage fluctuations (Ref 22, 23). The relationships between the current, voltage, and power observed among the torches under a constant gas flow rate are shown in Fig. 2. Figure 2 shows that the I-V (currentvoltage) characteristics of the cascade plasmas display an increasing trend, whereas the conventional plasma shows a decreasing trend after an initial increase. It is reported elsewhere (Ref 24) that the heat losses in the plasma torches are determined by convective heat transfer, arc radiation, and the heat flow occurring through the anode attachment spot of the arc. In case of typical plasma torches (conventional torch), the temperature at the arc root/anode attachment spot increases with increase in the input current (Ref 24); the local heating at the arc root attachment spot becomes very intensive above a threshold input current value. Such high localized heating at the arc root

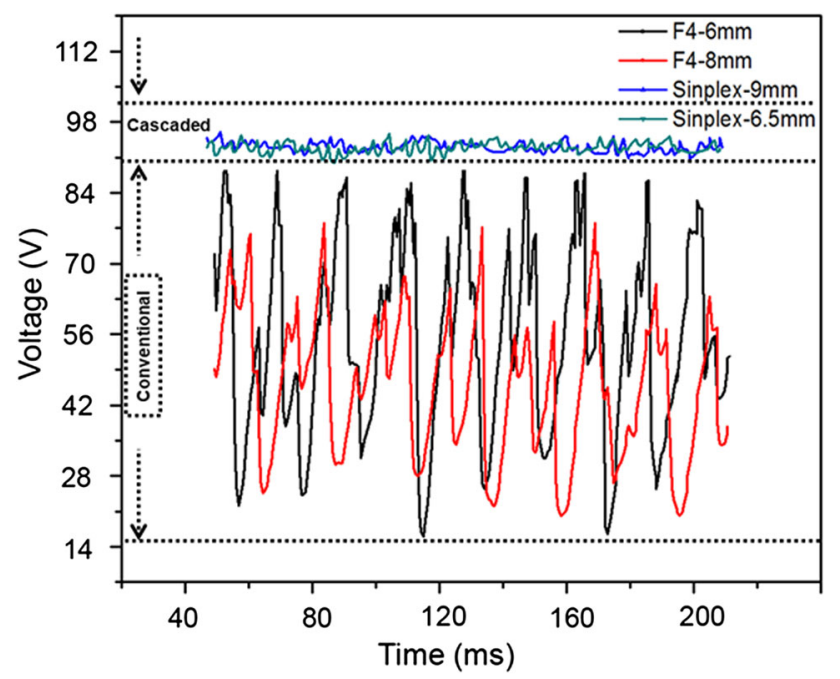

Fig. 1 Voltage fluctuations measured in the torches while operating under identical conditions attachment spot increases the electrical resistivity of the anode, leading to the voltage drop as shown in Fig. 2. In case of the cascaded torch, the neutrode stack (stack of insulated copper rings) makes the arc to jump to a longer distance and the ending of the arc attaches on to an anode ring. The long arc and low surface area of the anode ring restrict the arc oscillations and increase the stability of the arc (Ref 2). This condition averts the overheating of the anode ring and prevents the voltage drop from occurring at higher input current levels. Thus, the increasing type of I$\mathrm{V}$ trend found in the cascaded torch is significantly more efficient for spray deposition of coatings and it helps reduce anode erosion in comparison with the falling I-V characteristics of the conventional torches. The high I-P (current-power) slope of cascade torch (Fig. 2) indicates a steady laminar plasma generation and sustenance signifying a stable conversion of electrical energy into thermal energy or enthalpy.

\section{In-Flight Temperature and Velocity Diagnosis of Particles Sprayed Using Conventional and Cascaded Arc Torches}

In this study, the single particle sensor DPV 2000 was used to map the temperature and velocity distribution of the cross section of the particle laden plume and the ensemble sensor Accuraspray-g3 was used to measure the ensemble/ mean velocity and temperature of powders sprayed at high
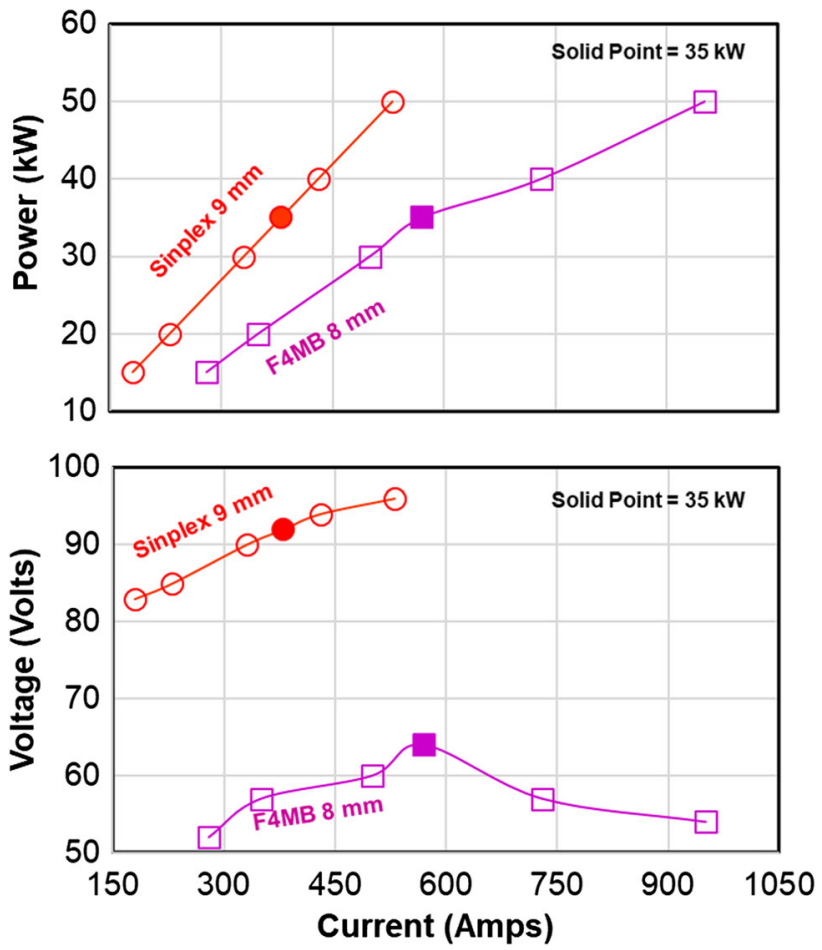

Fig. 2 Current-voltage and current-power relationships among torches operated under identical conditions 
feed rates. The plume cross section of the cascaded arc was large compared to a conventional torch; hence, a wide area temperature field mapping was carried out comprising of 81 points in which each point is separated by $5 \mathrm{~mm}$ as previously mentioned in the experimental part. Measurement time on each grid point was $10 \mathrm{~s}$, which allows for enough support of the mean and standard deviations by some hundreds of single particle data at least in the central grid area. Before starting the measurement, the gun was centered by the DPV-2000 auto-center function so that the pivotal point of the measurement grid $(x=0 \mathrm{~mm}$, $y=0 \mathrm{~mm}$ ) refers to the maximum intensity of the particle jet. The main aim of the wide area DPV-2000 temperature and velocity mapping was to capture the effect of voltage fluctuations on the in-flight particle temperature isotherms and velocity contours. The wide area mapping and the long data measurement time (10 s) employed at each grid point made this realizable as displayed in Fig. 3. Figure 3 shows that the plume of the cascaded arc torch is much wider, and the temperature isotherms, as well as the velocity contours, are more symmetric with a lesser number of particles entrapped in the eddies. Inline with expectation, the cascaded torch has a broader temperature isotherm with wider velocity contours and a circular plateau indicating greater plume stability, whereas the conventional torch has a narrower and sharper temperature peak as shown in Fig. 3, which is reinforced by the observations of Mauer et al. (Ref 25). A narrow/sharp temperature peak would have serious implications when the hardware undergoes degradation with an associated change in the plume positions and injection parameter leading to quality issues in the coatings. Broader isotherms and wider velocity contours are preferable because it should be less sensitive to hardware degradation. Irrespective of the nozzle sizes, the peak temperatures attained in the conventional torch are less compared to the cascade torch in addition to these many particles which are entrapped in the eddies generated around the center of the plasma plume of the conventional torch. From the literature, it is evident that the voltage fluctuations have been assumed to have the same amplitude and the same period, which of course induce a regular saw tooth shape for the power fluctuation and correspondingly the effective power (Ref 26). It was observed that the effect of these fluctuations was realizable on the velocity as well as on the temperature. The DPV temperature and velocity mapping results of conventional torch shown in Fig. 3 prove that arc root fluctuations could lead to segregation effects producing waves of 'cold' and 'hot' particles. Arc root fluctuations cause the particles to experience fluctuations in the plasma field during their exposure time (travel through plume), resulting in clusters/bursts of particles being exposed to an average higher or lower heat energy transfer. Furthermore, the large arc root fluctuations in conventional torch create vortex rings (eddies) whose coalescence results in an engulfment type process resulting in the turbulent velocity components and entrainment of cold gas from the surrounding atmosphere. This turbulent condition makes the injection somehow challenging in conventional plasma torch which would need additional momentum from the carrier gas to optimally inject the particle into the central axis of the plasma column. The impact of the plasma fluctuations on the in-flight particle state was evaluated by Bisson et al., by synchronizing the particle diagnostics with the torch voltage. Time-dependent particle temperature and velocity variations due to arc fluctuations, as large as Delta- $T=600{ }^{\circ} \mathrm{C}$ and Delta$V=200 \mathrm{~m} / \mathrm{s}$, were observed. Plasma fluctuations were found to be a prime source of statistical variance in the inflight particle velocity and temperature (Ref 26). Even though the present investigation does not involve synchronization of the DPV with the timescales of voltage measurements, the observations of the Bisson et al. are still applicable to this article as well due to the macroscopic coupling effect of voltage fluctuations on particle temperature and velocity. Influence of powder loading on plasma quenching is clearly realizable from the ensemble diagnostics results displayed in Fig. 4. Powder loading effect locally cools or quenches the thermal plasma. The threshold loading limit of cascaded arc (SX-9 mm) is $80 \mathrm{gpm}$ which far exceeds the loading limit of the conventional torch (F4MB $8 \mathrm{~mm}$ ) which had a saturation loading limit of $60 \mathrm{gpm}$. The smaller nozzles in both the configurations had a threshold loading limit of $40 \mathrm{gpm}$, but the temperature of particles sprayed with cascade was higher than the conventional. A well-anticipated matter that the temperature drop becomes significant when the powder mass flow rate exceeds the threshold loading limit is visualized in Fig. 4. Plasma quenching by powder loading is also clear from a decrease in the particle velocity (Fig. 4) because the particle velocity monotonically decreased with increased powder feed rate. It is worth emphasizing here that the temperature and velocity have coupled effect in APS process, especially when identical plasma conditions and different feed rates are used. In Fig. 4, it is noted that for both conventional and cascading torches, there is a general drop in both particle temperature and velocity with increasing feed rate. It is surmised that this relates to the reduced mean free path (causes inter-particle collisions and scattering) between the particles as feed rates are increased at a constant plasma condition which can reduce the effective heat and momentum transfer. This temperature and velocity loss can be significant when the powder mass flow rate exceeds half of the plasma mass flow rate (Ref 2). It was also proved by Shinoda et al. that when the inter-particle spacing becomes less than twice the particle diameter, the rate of heat transfer reduces due to inter-particle interactions ( $\operatorname{Ref} 12)$. 
Fig. 3 Wide area temperature and velocity field mapping of particles sprayed using different torches under equivalent condition
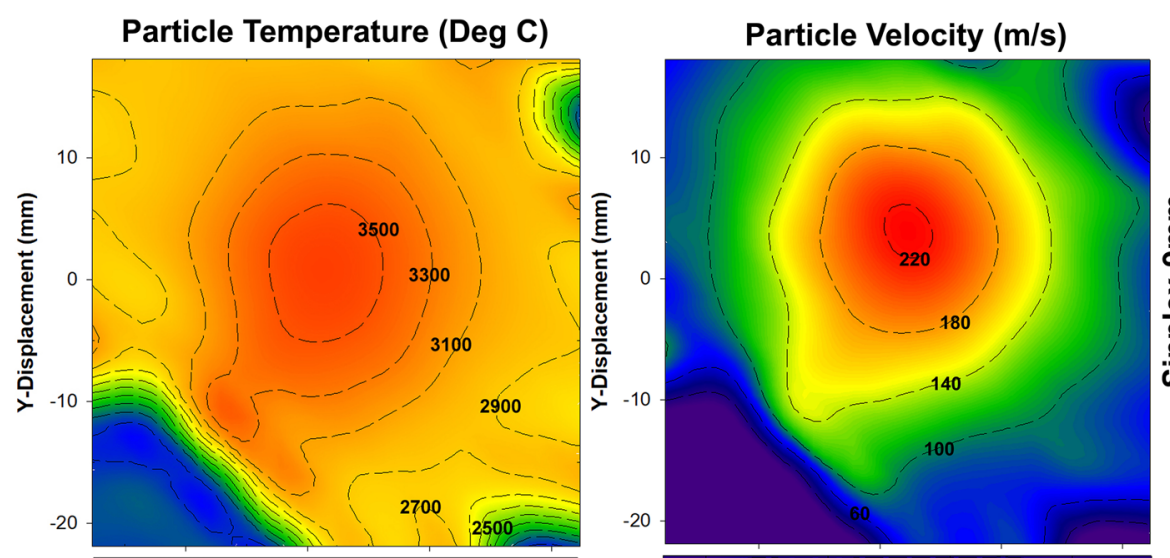

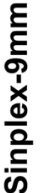
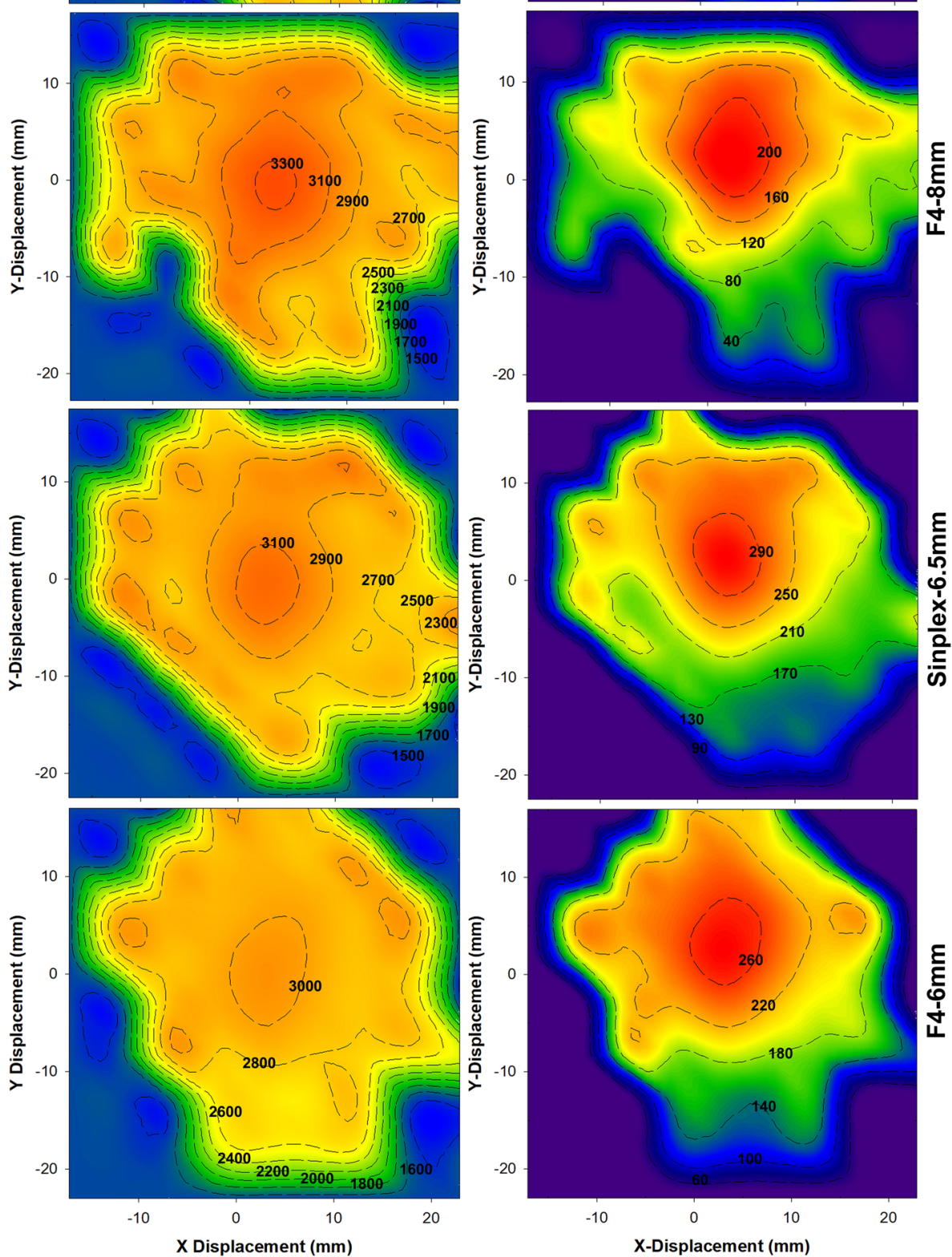


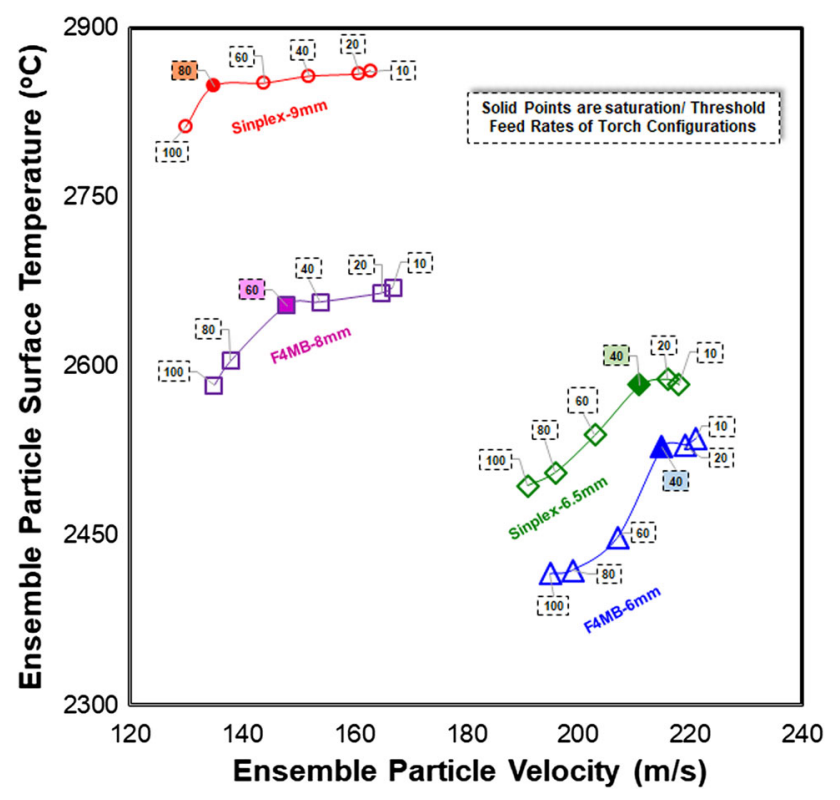

Fig. 4 Ensemble temperature and velocity measurement of particles sprayed using different torches under the equivalent condition

\section{In Situ Curvature Evolution and Stress Measurement on Coatings Sprayed Using Conventional and Cascaded Arc Torches}

In APS ceramic deposits, the quenching and thermal stresses are the two major sources of residual stress. These stresses are generated because of the rapid shrinkage and contraction of the molten splats during coating deposition stage and the material mismatch between the coating and the substrate in the post-deposition cooling stage, respectively. The quenching stress is always tensile, and its value is controlled by the characteristics of the impinging particles, substrate temperature, and stress relaxation mechanisms (Ref 27), whereas the state of thermal stress is dependent on the difference in the coefficient of thermal expansion (CTE) between the coating and substrate at the temperature gained by the specimen during spraying. In each stage of thermal spray, the substrate is deformed due to the misfit strain occurring at the coating-substrate interface, which helps the in situ curvature monitoring sensors for measuring the layer-by-layer stresses generated in the APS coatings (Ref 28). Using the curvature-thickness measurement, the quenching stress can be evaluated based on the assumption that the coating and substrate are deformed linearly, and considering that the coating layers are relatively thin compared to the substrate, the wellknown Stoney's formula was used to identify the coating stress and modulus (Ref 29). The thickness and curvature histories of the substrates during the spray deposition of coatings using the two different configurations of torches are displayed in Fig. 5. In general, the curvature change
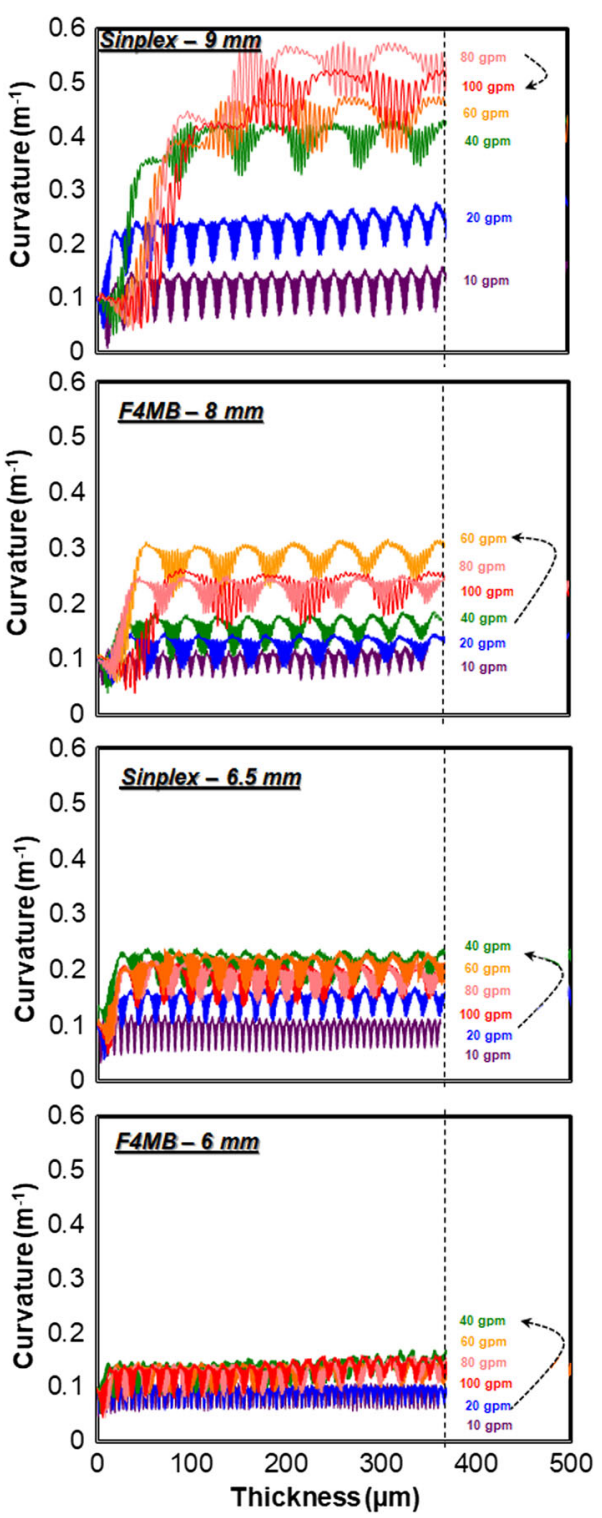

Fig. 5 Effect of torch configuration on in situ beam (substrate) curvature change during coating spray deposition

observed in coatings sprayed with cascaded arc torch was higher; it is also recognized that the curvature changes increase with the thickness of the deposit. Higher thickness per pass and curvature changes were observed in case of coatings sprayed with large diameter nozzles due to their higher efficiency associated with melting ability and vice versa is for coatings deposited with smaller nozzles. The first pass curvature changes which occur when the molten particles hit the virgin grit-blasted substrate are usually higher compared to the subsequent curvature changes occurring during coating deposition. It was proposed by Markus et al. (Ref 30) that the compressive residual stress created during grit blasting gets released, compounding along with the stresses generated during the application of 
the first pass. This stress superimposing/compounding effect is created due to the thermo-physical interaction of the hot particles with the grit-blasted surface. The first pass curvatures, as well as the subsequent changes in curvatures during coating deposition, were found to reflect the saturation loading limits. Once the threshold loading is exceeded, the first pass curvature change also starts to decrease as illustrated in Fig. 5. The effect of powder feed rate on the evolving stress and modulus of the coatings is shown in Fig. 6. A peak evolving stress and modulus values were attained at a threshold powder loading limit, and then, the stress and modulus start to decrease indicating the existence of a distinguishable plasma quenching regime for each of the torch configurations as shown in Fig. 6. Higher evolving stress indicates better inter-splat bonding, and it increases until the threshold powder limit is reached. Further beyond it, the particle melting gets influenced which increases un-melted particles and porosity, in turn, reducing the stress and modulus values. As expected, larger nozzle sizes resulted in more efficient melting and higher evolving stresses and elastic modulus of coatings due to denser architectures resulting from efficient melting and bonding of particles. Overall, cascaded arc plasma torch
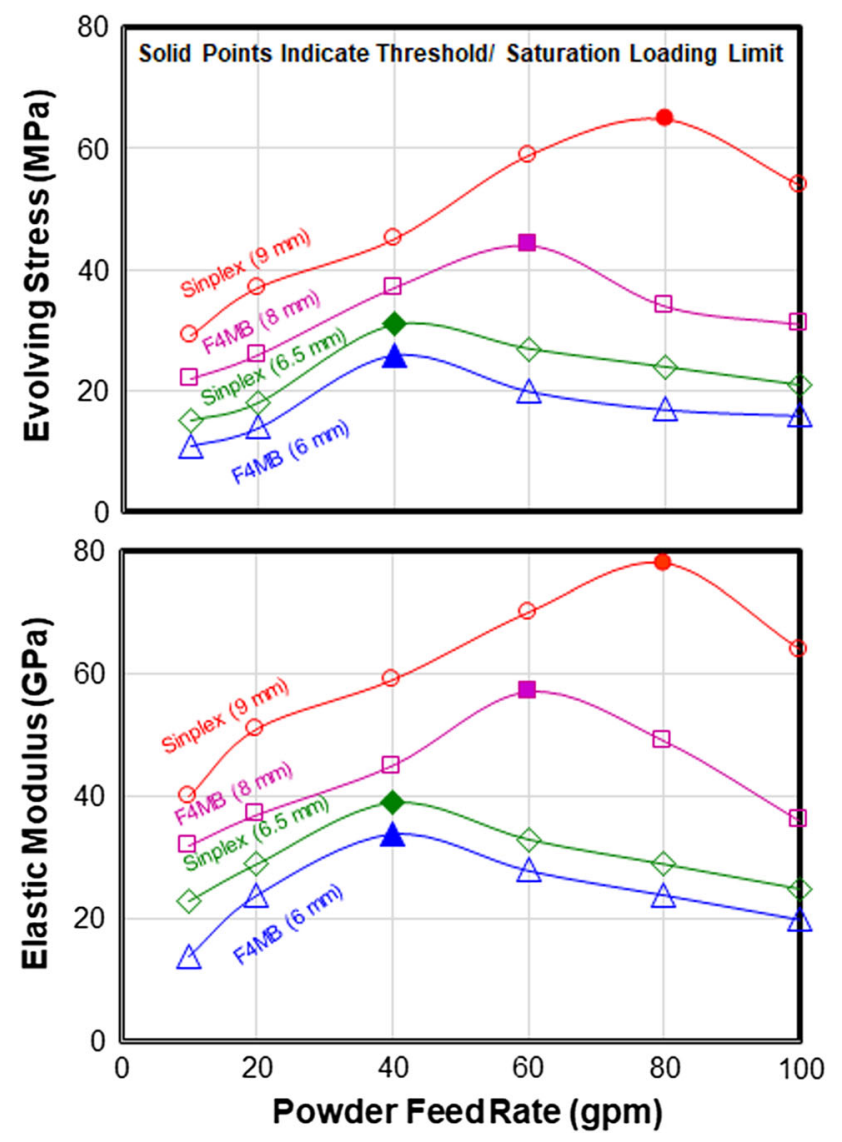

Fig. 6 Effect of feed rate and torch configurations on evolving stress and elastic modulus produces coatings with higher modulus than the conventional torch for similar feed rates as shown in Fig. 6.

\section{Evolution of Microstructures in Coatings Deposited Using Conventional and Cascaded Arc Torches}

It was noted that the microstructures of cascaded arc-deposited coatings are generally denser compared to conventional torch-deposited coatings. The microstructure relationships shown in Fig. 7 indicate that above the threshold powder loading limit, the powder particles do not melt well and impinge as un-melted or partially melted particles. This phenomenon increased porosities and solid particle entrapments in the coating deposits resulting in lower density and cohesion and thus lower evolving stress and modulus values. Figure 7 shows the cross-sectional morphologies of the coatings deposited using the cascade and conventional torches under different powder feed rates. The coating deposited at lower feed rate contains many horizontal interlamellar microcracks and micropores. The lower stress and modulus of these coatings observed in Fig. 7 are likely to be because of these defects. For an APS ceramic coating, it is generally believed that higher interface temperature and higher thickness per pass lead to denser microstructure through the coating (Ref 31,32 ). It should be mentioned that this phenomenon is valid up to the threshold feed rate. If the threshold feed rate is exceeded, two mechanisms will come into the picture. The first one is the coating becoming porous with the embedment of a large amount of partially melted and un-melted particles which would reduce the stress and in-plane modulus in the coatings. The second mechanism is the formation of segmentation cracks, which is related to the quenching stress relaxation occurring during coating deposition. The segmentation occurs when the strain energy stored in each pass increases significantly with the addition of passes. Further, the coating should have high density together with a higher thickness per pass. If these conditions are satisfied, then the strain energy reaches the fracture energy of the coating and the cracks will be generated during the deposition to relieve the accumulated tensile stresses (Ref 33). In the current investigation, the feedstock used is an extremely coarse HOSP YSZ powder; hence, the density required to generate segmentation is not satisfied, allowing the first mechanism to prevail as shown in Fig. 7. It is comprehensible that the densities of the coatings deposited by the two configurations of torches were found to increase until a saturation point is reached after which the coatings start to become porous again. The coatings deposited using cascade are much denser, and the threshold loading was attained post- $80 \mathrm{gpm}$ feed rate, whereas the threshold loading was $60 \mathrm{gpm}$ for the conventional torch. Furthermore, from the microstructural 
Fig. 7 Microstructures of the cascaded arc and conventional torch-sprayed deposits indicating the powder loading effect

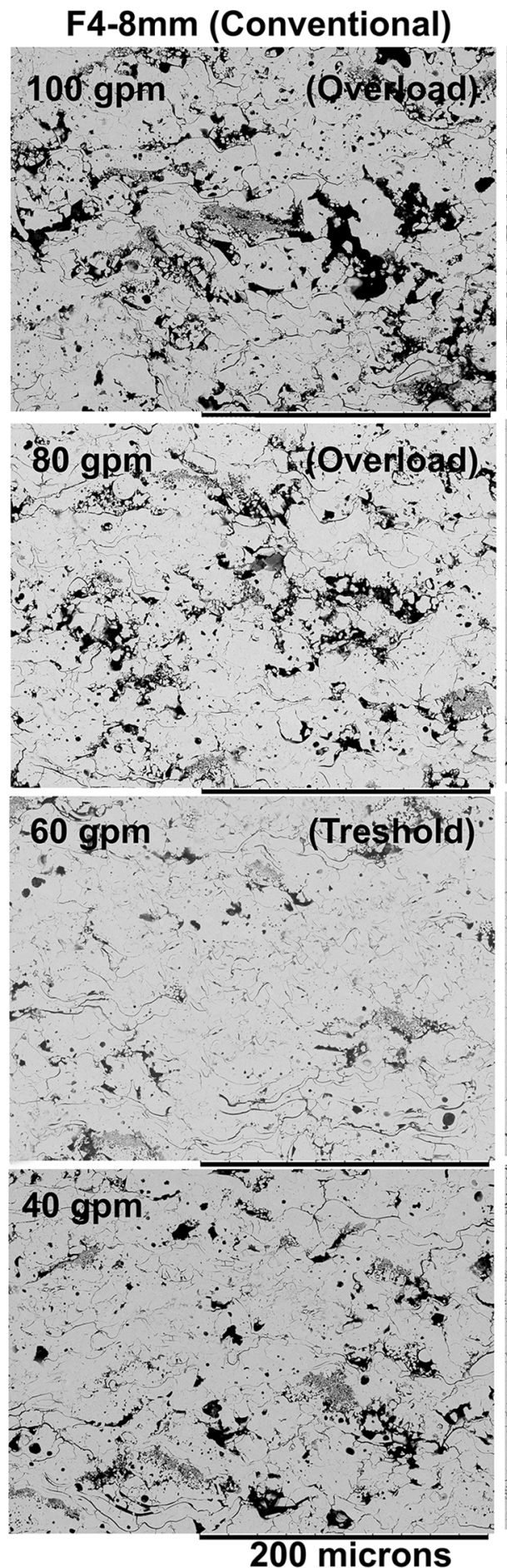

Sinplex-9mm (Cascade)
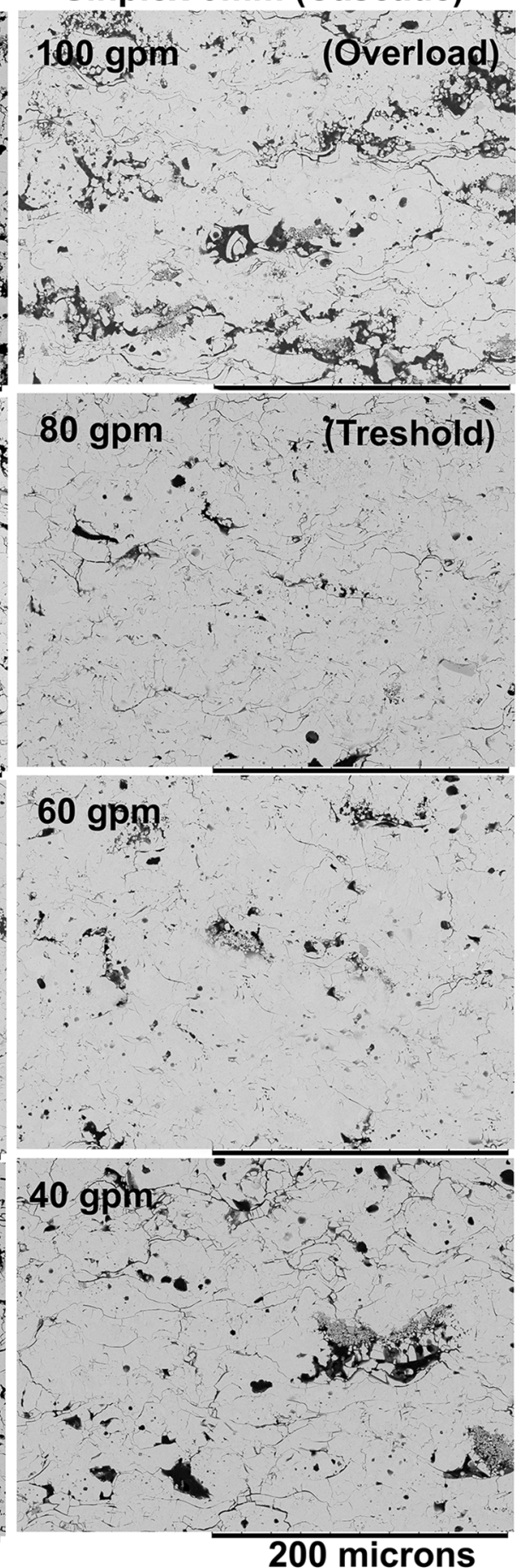

morphologies of the coatings deposited below and above saturation threshold (60 gpm for conventional and $80 \mathrm{gpm}$ for cascade torch), it was observed that the coatings sprayed below the saturation threshold have more horizontal interlamellar microcracks and micropores, whereas the coatings deposited above threshold loading were found to have lots of semi-molten and un-melted particles as shown in Fig. 7. The coating modulus is interconnected to the microstructure and residual stresses in the coating. The measured elastic moduli of the coatings in this investigation ranged between 10 and $78 \mathrm{GPa}$. The rise and fall of the modulus values were found to be consistent with the increase and decrease in the porosity/density values of the coatings (Fig. 6 and 7). 
Stress-Modulus Relationship Among Coatings Deposited Using Conventional and Cascaded Arc Torches

The in situ beam curvature monitoring system utilizes the curvature change occurring during post-deposition cooling to measure the coating modulus (Ref 10, 16). Figure 6 shows the elastic moduli of coatings deposited at different feed rates. Coating modulus increased up to the threshold loading limit and then starts to decrease after that. To determine the effect of evolving stress on the modulus, the results from Fig. 6 are combined and plotted as shown in Fig. 8. For the coatings deposited at different feed rates, the total target thicknesses were kept to an almost constant value of 350 microns. It was inferred that the in-plane elastic modulus of the coating increases with increase in the evolving stress displaying a linear correlation between the two properties as illustrated in Fig. 8. The coating modulus is linked to the microstructure and residual stresses in the coating (Ref 16). For the coating deposited with a smaller nozzle size, the higher porosity and density of microcracks lead to a lower modulus. For larger nozzle size, the coating modulus is controlled by the combination of the density of the microcracks and the volume of porosities. With the increase in the deposition temperature, the cohesion between splats in the coating increases, leading to the increment of the coating modulus. Moreover, the coating sprayed with cascaded arc plasma, due to its higher melting and deposition temperature, was found to exhibit higher stiffness due to more coherent structure (better bonding) between splats.

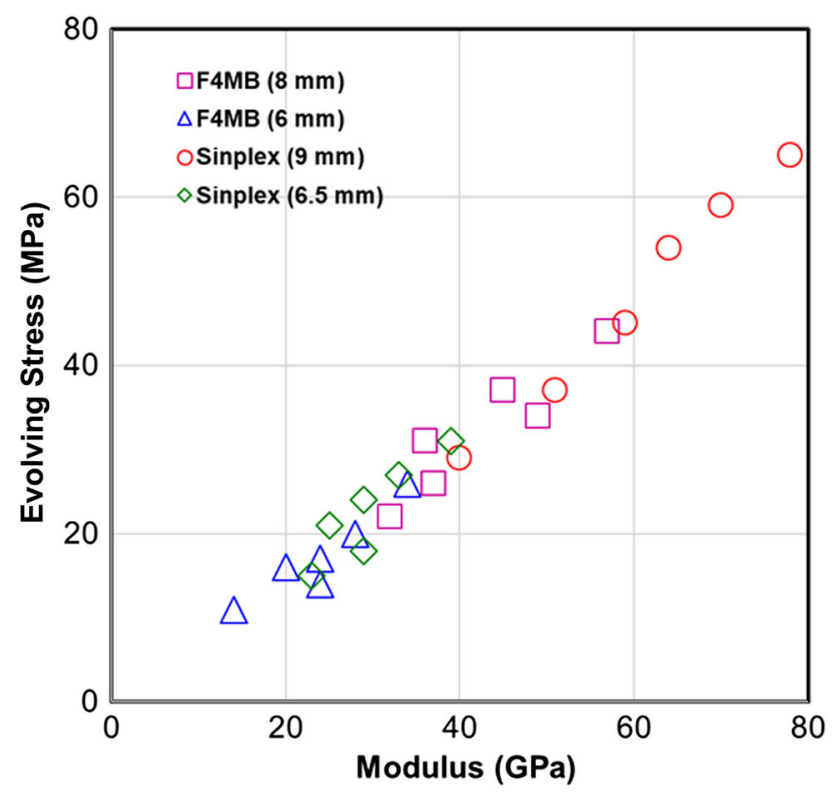

Fig. 8 Stress-Modulus Relationship among coatings

\section{Heat Flux Delivered by Conventional and Cascaded Arc Torches}

The results of experiments performed on the YSZ-coated beam heated by plasma are shown in Fig. 9. There is a linear increase in the plasma heat flux detected on the coated beam with the increase in the energy supplied by the torches. The cascaded arc plasma torch was recorded with higher heat flux values for both nozzle sizes. In the case of the 9-mm cascade, the lowest heat flux was $\sim 1300 \mathrm{kWm}^{-2}$ and the highest was $\sim 5300 \mathrm{kWm}^{-2}$. Within it in the full spectrum operational range, the heat flux values of cascaded arc torch are $\sim 1.5$ times higher than a conventional torch with comparable nozzle configuration as illustrated in Fig. 9. Such high heat fluxes can potentially modify the microstructure evolution. Specifically, when cascade torches are used, the surface of the coating under formation is subjected to very high plasma heat fluxes and reaches temperatures over $700-800{ }^{\circ} \mathrm{C}$ transitorily. Under these conditions, the un-melted particles, especially those traveling along fringes of the plasma plume, have the tendency to stick on to the hot surface of the previous layer thus increasing the spray deposition efficiency (Ref 34). In addition, the quality of contact between splats is enhanced because the hot lamellae of the previously deposited layer act as a nucleation site for the incoming impacting particles (Ref 35). The heat flux measured on the surface of the coating undergoing spray deposition is higher than plain heating as shown in Fig. 10 due to the involvement of conductive heat transfer arising from solidifying particles. The rapid quenching of the highly flattened splats releases

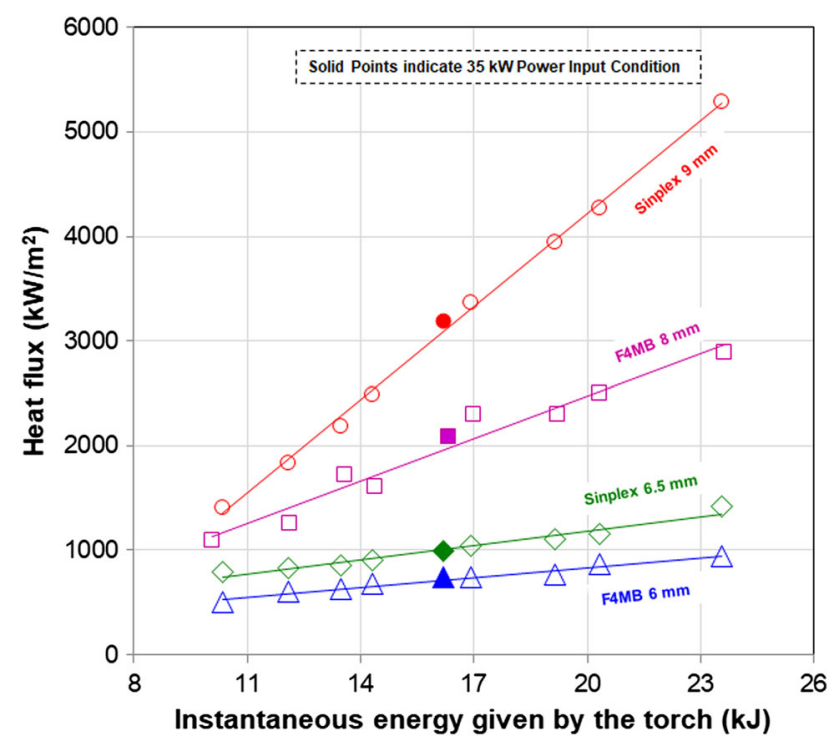

Fig. 9 Heat flux delivered by the torches on a YSZ-coated beam under equivalent plasma parameter settings 


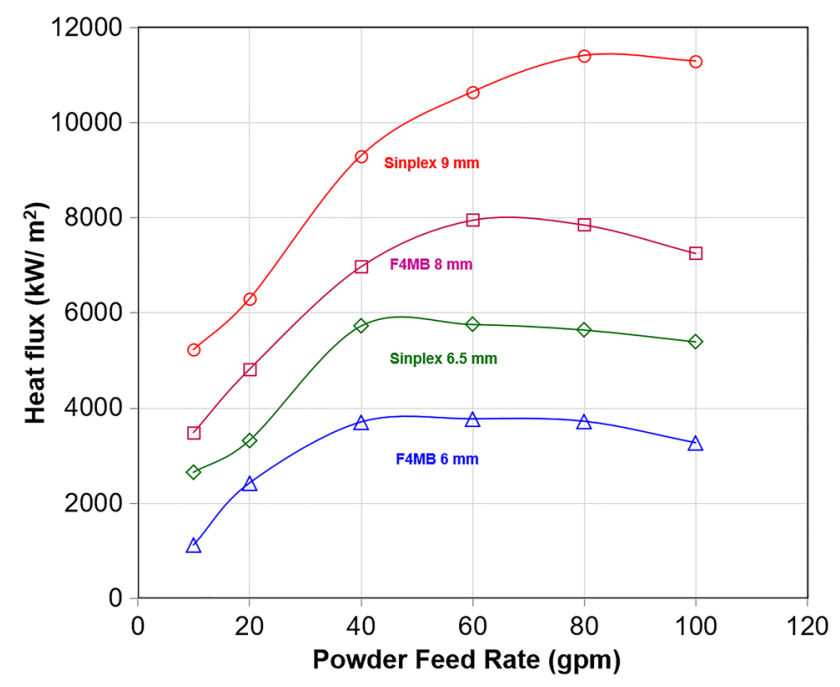

Fig. 10 Heat flux delivered by the torches during spray deposition of YSZ powder

their enthalpy into the metal substrate; in addition to this, the heat transferred to the substrate is also enhanced by the very high plasma heat flux (convective heat) directed by the cascade torch as shown in Fig. 10. The repeated heating of lamellae by the plasma plume also causes the sprayed droplets to remain on the substrate/coated surface under a high surface tension in a fluidic state which promotes the formation of a dense crystalline coating, as shown in Fig. 7. In all the considered feed rates, the cascaded torch seems to deliver higher heat flux on to the substrate surface as displayed in Fig. 10. Inline with expectation, the heat flux pattern almost follows the trend observed in the stressmodulus versus feed rate plot displayed in Fig. 6.

\section{Porosity and Thermal Conductivity Relationships Among Conventional and Cascaded Arc Plasma- Sprayed Coatings}

The thermal conductivity and porosity numbers of the coatings sprayed with the two different torch configurations under various powder feed rates are shown in Fig. 11. All the coatings deposited using conventional plasma torch show higher porosity and lower thermal conductivities than the cascaded arc plasma-sprayed coatings. In addition, a systematic increase in thermal conductivity and reduction in porosity of coatings were observed with increasing feed rates up to the threshold saturation feed limit after which the thermal conductivity reduces and porosity increases as illustrated in Fig. 11. The increase in thermal conductivity up to saturation point is primarily attributed to the reduction in defect population (porosity) in coatings. The coatings which were sprayed with cascaded arc torch have lower porosity without large opening dimensions, such as interlamellar and globular pores, and thus display a

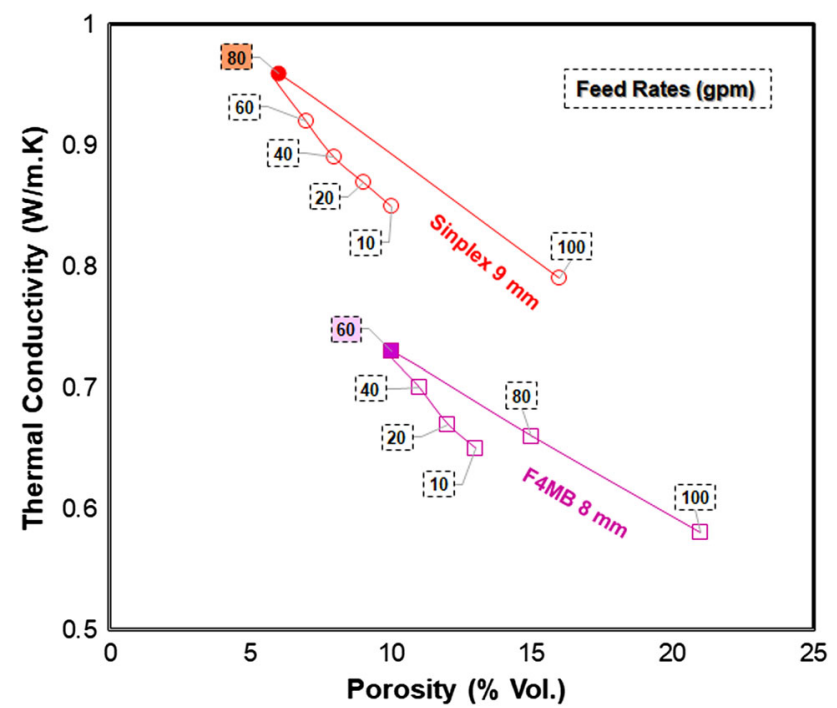

Fig. 11 Porosity and thermal conductivity relationships among conventional and cascaded arc plasma-sprayed coatings

concomitant increase in thermal conductivity. The normal trend expected in TBC also holds good here, i.e., the lower thermal conductivity corresponded to the coatings which had higher porosity and defects. This behavior is consistent with what has been reported earlier by other researchers (Ref 36). It was reported that the decrease in conductivity with defects/pores is associated with stronger phonon scattering (Ref 37). The presence of defects such as pore content, inter- and intra-lamellar cracks, partial and unmolten particles, etc., in conventional plasma spray coatings is higher; hence, such coatings would offer greater phonon scattering, resulting in lower thermal conductivity values as shown in Fig. 11. In general, it is observed that at high deposition rates, the contact between two splats is boosted by the higher localized deposition temperature, to such a degree that epitaxial columnar grain growth is observed within two splats (Ref 35 ). These regions assuredly are known to present an enhanced thermal conductivity. The features such as thinner lamellae and the presence of unmelts and partially melted or re-solidified particles have a major influence in determining both the thermal and mechanical properties of the coatings.

\section{Scaling Parameter to Get Equivalent Coating Properties of the Conventional Torch Through the Cascaded Arc Plasma Torch}

The thickness repeatability results of coatings sprayed with two kinds of torches with feed rates below and above threshold feed rates are illustrated in Fig. 12. It is noticeable that the thickness obtained per pass is much higher for cascaded arc plasma-sprayed coatings. The repeatability of coating thickness is also higher when the feed rates are 


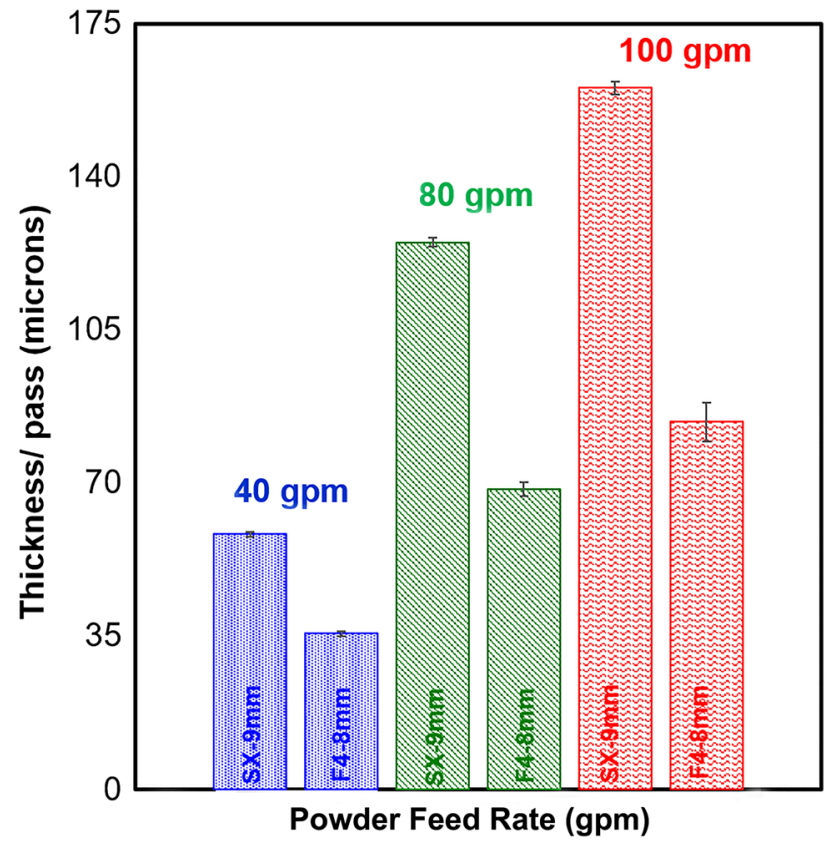

Fig. 12 Thickness repeatability results of coatings sprayed by the two different torch configurations

under the threshold limit as the cascade is more efficient in handling high throughputs. Given these differences in the way the two types of torches operate and resultant microstructure, it is of importance to contemplate a scaling parameter which can be used to obtain coatings which have equivalent microstructure and properties of the conventional torch through the cascaded arc plasma torch. The scaling parameter can help the industry to more effectively transition production to cascade technology. Following the stress and modulus data presented earlier, three coatings were sprayed with each of the torches under three equivalent power levels $(34,43$, and $51 \mathrm{~kW})$. The feed rate was maintained at $40 \mathrm{gpm}$, and the rest of the parameters were kept constant. Stress generated while spraying the above coatings was measured using in situ beam/substrate curvature measurement technique. A plot was constructed to relate the power levels and stress generated on the coatings sprayed via two different torches which are shown in Fig. 13. From Fig. 13, it was deduced that the stress developed in the cascade arc plasma-sprayed coatings is about 1.4 times higher than that of the stresses generated in coatings sprayed with a conventional torch under equivalent conditions. Following these, three more coatings were sprayed with the power level of the cascaded torch scaled down to nearly 1.4 times and the resultant coatings thus obtained had equivalent stress levels, deposition efficiency, and microstructures obtained from the conventional torch. The equivalency obtained in the power and stress levels of the cascade arc plasma-sprayed deposits is displayed in

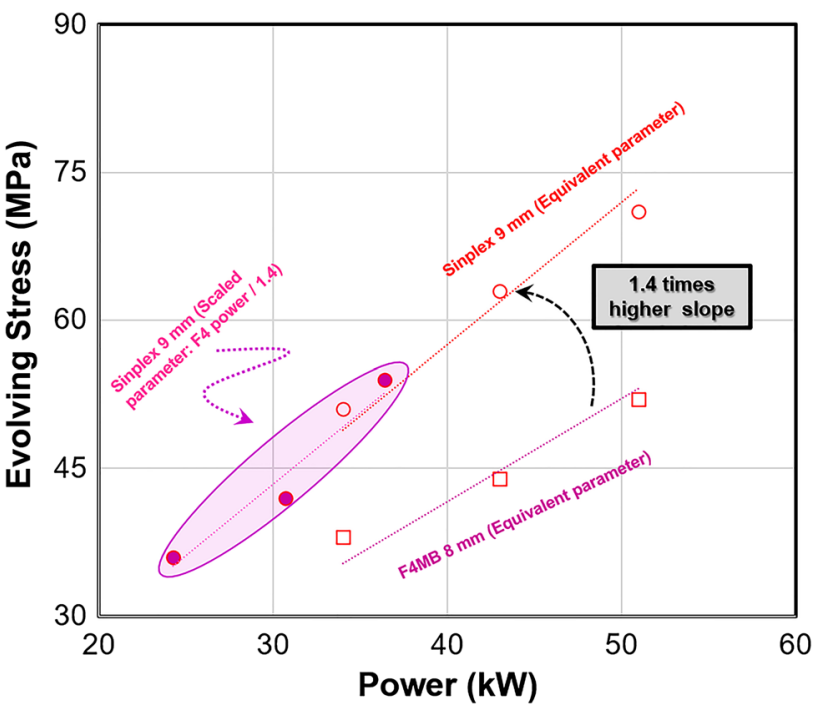

Fig. 13 Formulation of transformation/scaling parameter

Fig. 13. The scaling parameter obtained thus is shown in Eq 3.

Translational/Scaling parameter:Sinplex Power $=\mathrm{F} 4 \mathrm{MB}$ Power $/ 1.4$

This scaling parameter works well within $25-55 \mathrm{~kW}$ range for the Hollow Oxide Spherical Yttria-Stabilized Zirconia (HOSP-Metco 204C NS YSZ) powder provided when the gas flow rates, powder feed rates, application rates (raster speed and step size of the meander), spray distance are identical and with the optimized injection condition. Another reliability experiment was conducted to compare the repeatability of the coatings sprayed below, at, and above the threshold loading limit as shown in Fig. 14. The stress-modulus relationship plot shown in Fig. 14 illustrates that the variability of coatings in the stressmodulus space is narrower/tighter for cascaded arc plasmasprayed coatings; thus, the repeatability of coatings sprayed with cascaded arc torches is better even above the threshold/saturation loading limits, whereas the repeatability of the conventional arc plasma-sprayed coatings decreases with increasing powder feed rate as shown in Fig. 14. The solid points in the plot shown in Fig. 14 are properties of coatings sprayed with a cascaded torch with $24.5-\mathrm{kW}$ scaling (power) parameter which matches with the properties (including the microstructures) of coatings deposited using $35 \mathrm{~kW}$ with the conventional torch. The deposition efficiency of the coating sprayed by the cascade torch with the scaled parameter also matched with the conventional torch. The deposition efficiencies of the scaled parameter were measured to be at 46,34 , and $29 \%$ for the powder feed rates 40,80 , and 100 gpm, respectively. 
Fig. 14 Repeatability of coatings below and above threshold loading with equivalent and scaled parameters illustrating the stress-modulus and microstructure relationships
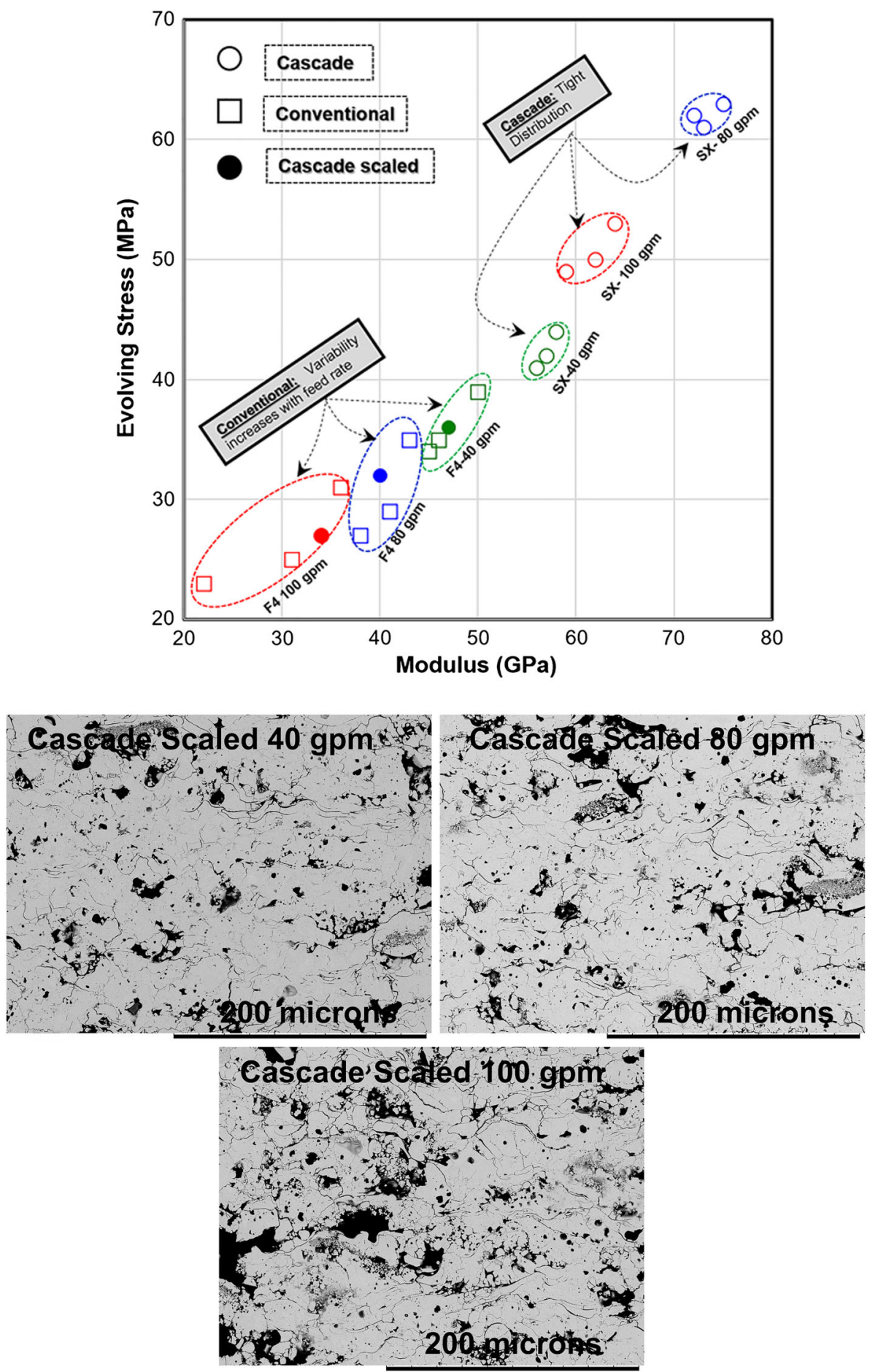

\section{Summary and Conclusion}

This study presents an integrated investigation of operational capabilities and resultant coating deposits associated with conventional and cascaded arc plasma processed ceramics. The comparisons of the conventional and cascaded arc plasma torches were conducted at various important stages of the plasma spray process using sensors that are widely accepted in the thermal spray industries. The analysis reported within this article addresses and highlights differences in plume particle interaction, material loading, coating stress evolution, microstructure, and properties between conventional and cascaded torches.

- The electrically insulating neutrode arrangement in the cascaded torch restricts the arc movement between the 
cathode and anode resulting in uniform heat and momentum transfer to the powder particles; this helps the cascaded arc plasma torch to attain a much more uniform spray plume as visualized in the DPV diagnostics results.

- The current-voltage characteristics of the cascade plasmas displayed an increasing trend, whereas the conventional plasma shows a decreasing trend. The high current-power slope of cascade torch indicates a steady and laminar plasma generation and sustenance signifying a stable conversion of electrical energy into thermal energy or enthalpy. The voltage fluctuation in the conventional torch causes the formation of a large number of eddies and turbulence in the plasma particle flux leading to inefficient melting. These changes in the temperature and velocities of the two torches are clearly captured in the first-order process map.

- There is a threshold/saturation feed rate for a set plasma condition at which the particle would start to locally cool the plasma. This threshold can be easily identified using saturating particle temperature and velocity values observed in the ensemble particle diagnostic measurement results and the saturating curvature values observed in the results derived from the in situ coating property measurements.

- Overall, the cascaded arc plasma produces coatings with higher stress and modulus than a conventional torch for similar feed rates. Possible effects of plasma quenching/threshold feed rates were also captured in stress-modulus second-order process map for both configurations of torches. The microstructures of cascaded arc-deposited coatings are generally denser compared to conventional torch-deposited coatings. The stress microstructure relationships show that above the threshold powder loading limit, the powder particles do not melt completely in-flight and are incorporated as un-melted particles in the coating. This phenomenon causes increased porosities and solid particle entrapments in the coating deposits resulting in lower stress (due to reduced cohesion) and modulus values.

- The major heat flux directed toward the substrate is contributed by the particles, and a minor amount of heat is contributed by the torch. In all the considered feed rates, the cascaded torch seems to deliver higher heat flux on to the substrate surface. The heat flux pattern almost follows the trend observed in the stress versus feed rate plot. There is a linear increase in the plasma heat flux detected on the coated beam with the increase in the energy supplied to the torches. The cascaded arc torch recorded higher heat flux value for both nozzle sizes. Within it in the full spectrum operational range, the heat flux values of cascaded arc torch are $\sim 1.5$ times higher than a conventional torch with comparable nozzle configuration.

- The repeatability of coatings sprayed with cascaded arc torches is generally improved even above the threshold/ saturation loading limits. The power of the cascaded torch is scaled down 1.4 times to get equivalent stressmodulus and microstructure of coatings deposited using a conventional torch. This relationship seems to work within $25-55 \mathrm{~kW}$ range. The scaling parameter can be used to get the equivalent coating properties deposited by conventional torch using the cascaded torch, and it is applicable to the powder used in this study, but the methodology adopted for establishing the scaling parameter is universal.

- These evaluations were focused on in-process voltage fluctuations, in-flight characteristics under different feed rates, as well as a sprayed coating test. The process evaluation strategy proposed in this investigation can be used as a validation and testing procedure to determine the stability of a torch and help the industries to adopt a new torch design for production applications efficiently in a robust and scientific manner.

Acknowledgment This work was supported by The Industrial Consortium for Thermal Spray Technology of Stony Brook University. The authors thank Dr. Raja Singaravelu for performing heat flux measurements and calculations. The internal discussions on sample preparation, coating property measurements, and evaluations with Dr. Vaishak Viswanathan, and Dr. Gopal Dwivedi are acknowledged. The authors appreciate the Oerlikon Metco Team: Dr. Richard Schmid, Michael Tobin, Dr. Jose Colmenares-Angulo, David Hawley, Ronald Molz, Riston Rocchio-Heller, and Jonathan Gutleber for the help and support in setting up Sinplex Pro Cascaded arc plasma torch and 9MC spray control system at the Centre for Thermal Spray Research (CTSR), Stony Brook University, New York.

\section{References}

1. H. Rob, Z. Wang, O. Kesler, L. Rose, J. Jankovic, S. Yick, R. Maric, and D. Ghosh, Thermal Plasma Spraying for SOFCs: Applications, Potential Advantages, and Challenges, J. Power Sour., 2007, 2(170), p 308-323

2. V. Armelle, C. Moreau, N.J. Themelis, and C. Chazelas, A Perspective on Plasma Spray Technology, Plasma Chem. Plasma Process., 2015, 3(35), p 491-509

3. S. Ghorui and A.K. Das, Origin of Fluctuations in Atmospheric Pressure Arc Plasma Devices, Phys. Rev., 2004, 2(69), p 2-6

4. X.H. Bing, L.L. Zheng, and T. Streibl, A Critical Assessment of Particle Temperature Distributions During Plasma Spraying: Numerical Studies for YSZ, Plasma Chem. Plasma Process., 2006, 1(26), p 53-72

5. O.P. Solonenko and M.F. Zhukov, Investigation and Design of Thermal Plasma Generators, Thermal Plasma and New Materials Technology, 1st ed., O.P. Solonenko, Ed., Cambridge Interscience Publishing, Cambridge, 1994, p 509-515

6. M. Javad and M.I. Boulos, Thermal Plasma Sources: How Well are They Adapted to Process Needs? Plasma Chem. Plasma Process., 2015, 3(35), p 421-436 
7. J.L. Marqués, G. Forster, and J. Schein, Multi-Electrode Plasma Torches: Motivation for Development and Current State-of-theArt, Open Plasma Phys. J., 2009, 1(2), p 89-98

8. D. Hawley, R. Molz, and D. Chen, Evaluating a Single Arc Cascaded Plasma Gun, Thermal Spray 2012: Proceedings of the International Thermal Spray Conference, Air, Land, Water, and the Human Body: Thermal Spray Science and Applications, B.R. Marple, A. Agarwal, L. Filofteia-Toma, M.M. Hyland, Y.-C. Lau, C.-J. Li, R.S. Lima, and A. McDonald, Ed., Springer, Houston, Texas, 2013, p 886-891

9. J. Matejicek, S. Sampath, P.C. Brand, and H.J. Prask, Quenching, Thermal and Residual Stress in Plasma Sprayed Deposits: NiCrAlY and YSZ Coatings, Acta Mater., 1999, 2(47), p 607-617

10. G. Dwivedi, T. Nakamura, and S. Sampath, Controlled Introduction of Anelasticity in Plasma-Sprayed Ceramics, J. Am. Ceram. Soc., 2011, 1(94), p 104-111

11. E. Nogues, M. Vardelle, P. Fauchais, and P. Granger, Arc Voltage Fluctuations: Comparison Between Two Plasma Torch Types, Surf. Coat. Technol., 2008, 18(202), p 4387-4393

12. S. Kentaro, Y. Tan, and S. Sampath, Powder Loading Effects of Yttria-Stabilized Zirconia in Atmospheric dc Plasma Spraying, Plasma Chem. Plasma Process., 2010, 6(30), p 761-778

13. V. Srinivasan, M. Friis, A. Vaidya, T. Streibl, and S. Sampath, Particle Injection in Direct Current Air Plasma Spray: Salient Observations and Optimization Strategies, Plasma Chem. Plasma Process., 2007, 5(27), p 609-623

14. Z. Lidong, K. Seemann, A. Fischer, and E. Lugscheider, Study on Atmospheric Plasma Spraying of $\mathrm{Al}_{2} \mathrm{O}_{3}$ Using On-line Particle Monitoring, Surf. Coat. Technol., 2003, 2-3(168), p 186-190

15. S. Sampath, V. Srinivasan, A. Valarezo, A. Vaidya, and T. Streibl, Sensing, Control, and In Situ Measurement of Coating Properties: An Integrated Approach Toward Establishing Process-Property Correlations, J. Therm. Spray Technol., 2009, 2(18), p 243-255

16. J. Matejicek, S. Sampath, D. Gilmore, and R. Neiser, In Situ Measurement of Residual Stresses and Elastic Moduli in Thermally Sprayed Coatings: Part 2: Processing Effects on Properties of Mo Coatings, Acta Mater., 2003, 3(51), p 873-885

17. C.S. Ramachandran, G. Dwivedi, V. Viswanathan, and S. Sampath, Characterizing Suspension Plasma Spray Coating Formation Dynamics through Curvature Measurements, J. Therm. Spray Technol., 2016, 8(25), p 1666-1683

18. V. Alfredo and S. Sampath, An Integrated Assessment of Process-Microstructure-Property Relationships for Thermal-Sprayed NiCr Coatings, J. Therm. Spray Technol., 2011, 6(20), p 12441258

19. T. Claire, C. Tixier, P. Tristant, J. Desmaison, and P. Leprince, Atmospheric Pressure Plasmas: A Review, Spectrochim. Acta, Part B, 2006, 1(61), p 2-30

20. I. Toru, P. Cronin, D. Bendix, and J.V.R. Heberlein, Anode Attachment Stability and Anode Heat Transfer for High-Intensity Arcs with the Lateral Gas Flow, IEEE Trans. Plasma Sci., 2005, 3(33), p 1123-1128

21. Z. Duan and J. Heberlein, Arc Instabilities in a Plasma Spray Torch, J. Therm. Spray Technol., 2002, 1(11), p 44-51

22. C.A. Jose, R. Molz, D. Hawley, and C.S. Ramachandran, Thorium-Free Versus Thoriated Plasma Gun Electrodes: Statistical
Evaluation of Coating Properties, J. Therm. Spray Technol., 2016, 4(25), p 622-630

23. J. Schein, M. Richter, K.D. Landes, G. Forster, J. Zierhut, and M. Dzulko, Tomographic Investigation of Plasma Jets Produced by Multielectrode Plasma Torches, J. Therm. Spray Technol., 2008, 3(17), p 338-343

24. M.F. Zhukov and I.M. Zasypkin, Thermal Plasma Torches: Design, Characteristics, Application, M.F. Zhukov, Ed., Cambridge Interscience Publishing, 2007

25. G. Mauer, R. Vaßen, and D. Stöver, Comparison and Applications of DPV-2000 and Accuraspray-g3 Diagnostic Systems, J. Therm. Spray Technol., 2007, 3(16), p 414-424

26. J.F. Bisson, B. Gauthier, and C. Moreau, Effect of Plasma Fluctuations on In-Flight Particle Parameters, J. Therm. Spray Technol., 2003, 1(12), p 38-43

27. S. Kuroda and T.W. Clyne, The Quenching Stress in Thermally Sprayed Coatings, Thin Solid Films, 1991, 1(200), p 49-66

28. Y.C. Tsui and T.W. Clyne, An Analytical Model for Predicting Residual Stresses in Progressively Deposited Coatings Part 1: Planar Geometry, Thin Solid Films, 1997, 1(306), p 23-33

29. T.W. Clyne and S.C. Gill, Residual Stresses in Thermal Spray Coatings and Their Effect on Interfacial Adhesion: A Review of Recent Work, J. Therm. Spray Technol., 1996, 4(5), p 401-405

30. M. Markus, G. Mauer, R. Mücke, R. Vaßen, H.C. Back, and J. Gibmeier, Investigations on the Initial Stress Evolution During Atmospheric Plasma Spraying of YSZ by In Situ Curvature Measurement, J. Therm. Spray Technol., 2016, 4(25), p 672-683

31. V. Robert, F. Traeger, and D. Stöver, Correlation Between Spraying Conditions and Microcrack Density and Their Influence on Thermal Cycling Life of Thermal Barrier Coatings, J. Therm. Spray Technol., 2004, 3(13), p 396-404

32. C.S. Ramachandran, V. Balasubramanian, and P.V. Ananthapadmanabhan, Multiobjective Optimization of Atmospheric Plasma Spray Process Parameters to Deposit Yttria-Stabilized Zirconia Coatings Using Response Surface Methodology, $J$. Therm. Spray Technol., 2011, 3(20), p 590-607

33. G. Hongbo, S. Kuroda, and H. Murakami, Microstructures and Properties of Plasma-Sprayed Segmented Thermal Barrier Coatings, J. Am. Ceram. Soc., 2006, 4(89), p 1432-1439

34. M. Michael and O. Kesler, Influence of Plasma Heat Flux on Segmentation Cracking and Permeability of Thin Suspension Plasma Sprayed Coatings, Surf. Coat. Technol., 2013, 1(216), p 289-296

35. S. Sampath, X.Y. Jiang, J. Matejicek, A.C. Leger, and A. Vardelle, Substrate Temperature Effects on Splat Formation, Microstructure Development and Properties of Plasma Sprayed Coatings Part I: A Case Study for Partially Stabilized Zirconia, $J$. Mater. Sci. Eng. A, 1999, 1(272), p 181-188

36. N.P. Padture, M. Gell, and E.H. Jordan, Thermal Barrier Coatings for Gas Turbine Engine Applications, Science, 2002, 296(5566), p 280-284

37. D.R. Clarke, Materials Selection Guidelines for Low Thermal Conductivity Thermal Barrier Coatings, Surf. Coat. Technol., 2003, 1(163), p 67-74

Publisher's Note Springer Nature remains neutral with regard to jurisdictional claims in published maps and institutional affiliations. 